\title{
ERBB4 exonic deletions on chromosome $2 q 34$ in patients with intellectual disability or epilepsy
}

\author{
Zerin Hyder $\mathbb{1}^{1} \cdot$ Wim Van Paesschen ${ }^{2,3} \cdot$ Ataf Sabir $^{4} \cdot$ Francis H. Sansbury $\mathbb{D}^{5} \cdot$ Katherine B. Burke ${ }^{5}$ Naz Khan ${ }^{1}$. \\ Kate E. Chandler ${ }^{1,6} \cdot$ Nicola S. Cooper $^{4} \cdot$ Ronnie Wright $^{1} \cdot$ Edward McHale $^{1} \cdot$ Hilde Van Esch $\mathbb{D}^{7} \cdot$ Siddharth Banka $^{1,6}$
}

Received: 28 July 2020 / Revised: 9 December 2020 / Accepted: 19 January 2021 / Published online: 18 February 2021

(c) Crown 2021. This article is published with open access

\begin{abstract}
ERBB4 encodes the tyrosine kinase receptor HER4, a critical regulator of normal cell function and neurodevelopmental processes in the brain. One of the key ligands of HER4 is neureglin-1 (NRG1), and the HER4-NRG1 signalling pathway is essential in neural crest cell migration, and neuronal differentiation. Pharmacological inactivation of HER4 has been shown to hasten the progression of epileptogenesis in rodent models, and heterozygous ERBB 4 null mice are shown to have cognitive deficits and delayed motor development. Thus far there is only a single case report in the literature of a heterozygous $E R B B 4$ deletion in a patient with intellectual disability (ID). We identified nine subjects from five unrelated families with chromosome $2 \mathrm{q} 34$ deletions, resulting in heterozygous intragenic loss of multiple exons of $E R B B 4$, associated with either non-syndromic ID or generalised epilepsy. In one family, the deletion segregated with ID in five affected relatives. Overall, this case series further supports that haploinsufficiency of ERBB4 leads to non-syndromic intellectual disability or epilepsy.
\end{abstract}

\section{Introduction}

Human ERBB4 is located on chromosome 2q34, has 28 exons, encodes at least five protein coding transcripts and is highly constrained against loss-of-function variants, with a

Zerin Hyder

zerin.hyder@mft.nhs.uk

1 Manchester Centre for Genomic Medicine, St Mary's Hospital, Manchester University NHS Foundation Trust, Manchester, UK

2 Department of Neurology, University Hospitals Leuven, Leuven, Belgium

3 Laboratory for Epilepsy Research, Katholieke Universiteit Leuven, Leuven, Belgium

4 West Midlands Regional Genetics Service, Birmingham Women's and Children's NHS Foundation Trust, Birmingham, UK

5 All Wales Medical Genomics Service, NHS Wales Cardiff and Vale University Health Board, Institute of Medical Genetics, University Hospital of Wales, Cardiff, UK

6 Division of Evolution \& Genomic Sciences, School of Biological Sciences, Faculty of Biology, Medicine and Health, University of Manchester, Manchester, UK

7 Center for Human Genetics, University Hospitals Leuven, University of Leuven, Leuven, Belgium
pLI (probability of loss-of-function intolerance) score of 1 [1]. It encodes a tyrosine kinase receptor HER4, a crucial regulator of cell function and neurodevelopmental processes in the brain. A vital ligand of HER4 is neureglin-1 (NRG1), and the HER4-NRG1 signalling pathway is critical in the migration of neural crest cells, and neuronal and glial differentiation [2]. HER4 is expressed in many adult and foetal tissues, with high expression in the brain and heart [3, 4].

Kasnauskiene et al. described a 15-year-old male patient with hyperactivity, intellectual disability (ID) and severe speech delay with a de novo $958 \mathrm{~kb} 2 \mathrm{q} 34$ deletion resulting in loss of exons 1-3 of ERBB4 (OMIM 600543) [5]. Backx et al. reported a de novo balanced translocation $\mathrm{t}(2 ; 6)(\mathrm{q} 34$; p25.3) in a girl with early onset myoclonic encephalopathy and profound psychomotor delay [6]. The 2q34 breakpoint was located between exons 1 and 2 of ERBB4, which was proposed to be the major driver of the phenotype. Walsh et al. described a $399 \mathrm{~kb}$ deletion of the distal region of $E R B B 4$ in a patient with schizophrenia, resulting in loss of exons 20-28 [7]. Array comparative genomic hybridisation (array-CGH) in a large cohort of patients with autism spectrum disorder identified two patients with intronic deletions of ERBB4 [8]. A meta-analysis by Feng et al. identified an ERBB4 intronic single nucleotide polymorphism, rs707284, in association with schizophrenia [odds 
ratio $=0.91,95 \%$ CI: 0.83-0.99, $P=0.035$ ] [9]. Takahashi et al. identified heterozygous $E R B B 4$ missense variants in three separate families with amyotrophic lateral sclerosis (ALS) [10]. Although ERBB4 variants have been implicated in several neurological phenotypes, their significance has not been proven conclusively.

\section{Methods}

\section{Case ascertainment}

Informed consent was obtained from the probands or guardians of all investigated subjects. Family 1 was ascertained at the Manchester Centre for Genomic Medicine. Written consent was from obtained from Family 1 (Research Ethics Committee (REC) number 11/H1003/3). Additional cases were ascertained through the DECIPHER (Database of Chromosomal Imbalance and Phenotype in Humans using Ensembl Resources) (accessed 9th February 2020) database, by interrogating for high-confidence deletions exclusively affecting ERBB4 in individuals with no other pathogenic or potentially pathogenic Copy number variants (CNVs) [11]. Clinical phenotypes were collected using a bespoke proforma. The logarithm of odds (LOD) score was calculated in Family 1 according to the formula $\mathrm{LOD}=\log 10 \frac{\Theta^{\mathrm{R}}\left(1-\Theta^{\mathrm{NR}}\right)}{(\Theta=0.5)^{\mathrm{R}+\mathrm{NR}}}$.

\section{Microarray and fluorescent in situ hybridisation}

High-resolution whole-genome array-CGH was performed using DNA extracted from peripheral blood using the Oxford Gene Technology Cytosure constitutional version 3 Array, to investigate Families 1, 2 and 5. For the assessment of Family 3, array-CGH was carried out using the BlueGnome 8x60k v2.0 ISCA platform. Test DNA was referenced against same-sex control DNA and data was analysed in BlueFuse Multi v4.1. The 180k Cytosure ISCA v2 array was used to assess the proband in Family 4. Where required, $2 q 34$ fluorescence in situ hybridisation (FISH) studies were performed using standard techniques.

\section{Results}

\section{Case report}

\section{Family 1}

Patient I:1 was a 61-year-old male referred to the clinical genetics service with ID. He demonstrated minor problems in attention, mild linguistic difficulties and problems with reading, writing, spelling and calculation. A detailed neuropsychological assessment identified primary problems with executive functioning, though his memory was relatively good and there were no notable problems with visuospatial functioning. He had six children, four of whom have ID (Fig. 1A). His second child (Family 1, Patient II:2 in Fig. 1A), was born at 38 weeks gestation with a birth weight of $3.03 \mathrm{~kg}$. There were no neonatal concerns. She was reported to have speech delay and mild motor delay. She sat by 7 months and walked by two and a half years. She was diagnosed with moderate to severe learning difficulties and attended a special educational needs school. At the age of 24 years, she could understand simple instructions and read short sentences. She required help with most activities of daily living including showering, toileting and dressing. Her behaviour was unpredictable with irritability and aggressive outbursts. She has one daughter, III:3, who had normal developmental milestones at the age of 2 years. Patient II:3 was born at full term by normal delivery, with a birth weight of $2.72 \mathrm{~kg}$. He had moderate speech delay. He sat by 7 months and walked by 18 months. He attended a special school. At the age of 23 , he was noted to have unpredictable behaviour with episodes of aggression. Patient II:5 is the fourth child of Patient 1-I. He spoke his first words by 3 years of age and walked by 18 months. He attended a special educational needs school. Patient II:6 was born at full term with a birth weight of $3.17 \mathrm{~kg}$. The pregnancy was complicated by maternal jaundice. He was able to speak in sentences by 7 years of age and walked by 2 years of age. He was noted to have severe behavioural problems and aggression. At the age of 16 years, he was studying Foundation level maths at College. All affected individuals including the proband were non-dysmorphic with normal growth parameters and a normal general and neurological examination. Individuals II: 1 and II:4 in this family attained developmental milestones within normal limits, attended mainstream schools and did not have ID.

An array-CGH in Patient I:1 identified a chromosome 2q34 deletion of 276.5 kilobases $(\mathrm{kb})$ encompassing exon 1 (numbered as in NM_005235.3 and demarcated from g.213403173_213403565 in GRCh 37) of ERBB4 (NC_000002.11:g.(213170347_213255794)_(213532234_ 213581360)del) (DECIPHER ID: 271941). Further arrayCGH and fluorescent in situ hybridisation (FISH) studies showed that the deletion was present in all affected individuals and absent in all unaffected individuals who were tested (Fig. 1A). The LOD score for the association of the deletion with the phenotype in this family was calculated as 1.81 (recombination factor $(\boldsymbol{\Theta})=0$; the number of informative meiosis/individuals $(N)=6$, and the number of recombinants $(R)=0$ ). 


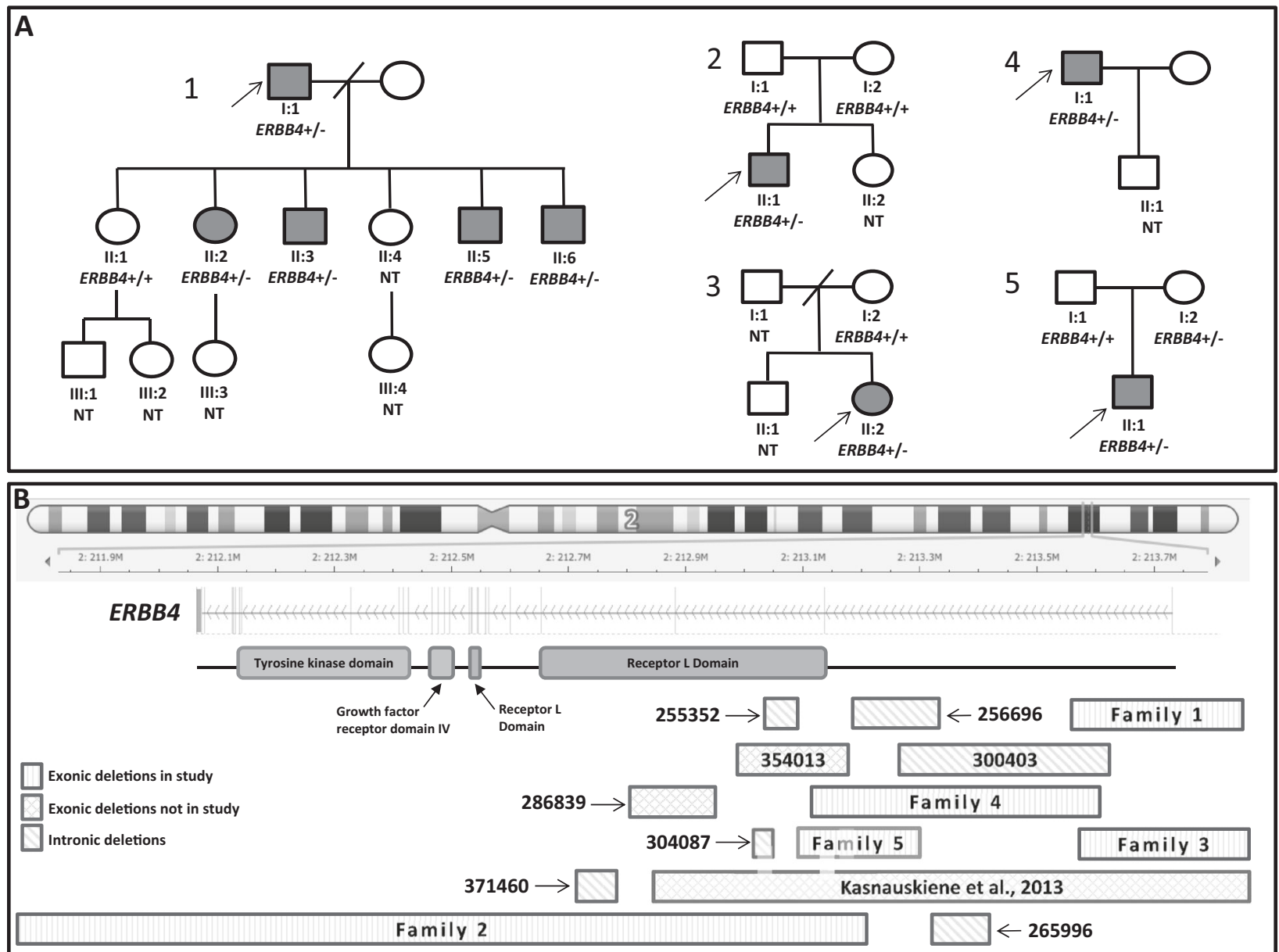

Fig. 1 Pedigrees of families described in this paper and 2 q34 deletions that exclusively involve ERBB4. A Pedigrees of Families $1-5$. Shaded boxes depict subjects with intellectual disability or epilepsy; NT indicates not tested. ERBB4+/+ indicates two wild-type alleles; $E R B B 4+/-$ indicates the presence of heterozygous ERBB4

\section{ERBB4 exonic deletions identified from DECIPHER}

We identified 12 additional deletions exclusively encompassing ERBB4 from DECIPHER (Table 1) (Fig. 1). Of these, six deletions involved at least one exon of ERBB4 and six were exclusively intronic. Out of six exonic deletions, two were shown to have occurred de novo, and one was maternally inherited. We collected more phenotype details in four of these families with exonic deletions (Families 2-5), which are summarised below as additional case reports.

\section{Additional case reports}

\section{Family 2}

Patient II:1 (Fig. 1A) was the second child of healthy, nonconsanguineous parents of normal intellect. Pregnancy was complicated by a urinary tract infection in the third exonic deletion. B Ideogram of chromosome 2 depicting DECIPHER deletions. Exonic deletions included in our study are illustrated with red boxes with vertical lines; exonic deletions not included in our study are orange boxes with hatched lines; and purely intronic deletions are green boxes with diagonal lines.

trimester. He was born at 41 weeks gestation by normal delivery with a birth weight of $3.71 \mathrm{~kg}$. He manifested speech delay and required speech and language therapy from the age of 3 years. He was able to speak in short sentences by 4 years of age. He attended a mainstream school with extra support; his school age was 1 year behind his chronological age. At 11 years of age, he could speak in short sentences and understand simple instructions. He had some behavioural difficulties such as irritability and angry outbursts. On examination, he had no significant dysmorphic features. His head circumference was $54.2 \mathrm{~cm}$ (25th centile), height $149 \mathrm{~cm} \mathrm{(50-75th} \mathrm{centile)} \mathrm{and}$ weight $40 \mathrm{~kg}$ (50-75th centile). Array-CGH in Patient II:1 identified a chromosome $2 \mathrm{q} 34$ deletion of $1.15 \mathrm{Mb}$ encompassing exons 2-28 of ERBB4 (NC_000002.11:g. (211787769_211901530)_(213054251_213106838)del).

FISH studies performed on blood samples from both parents for the ERBB4 deletion indicated that this CNV arose de novo in Patient II-1. 


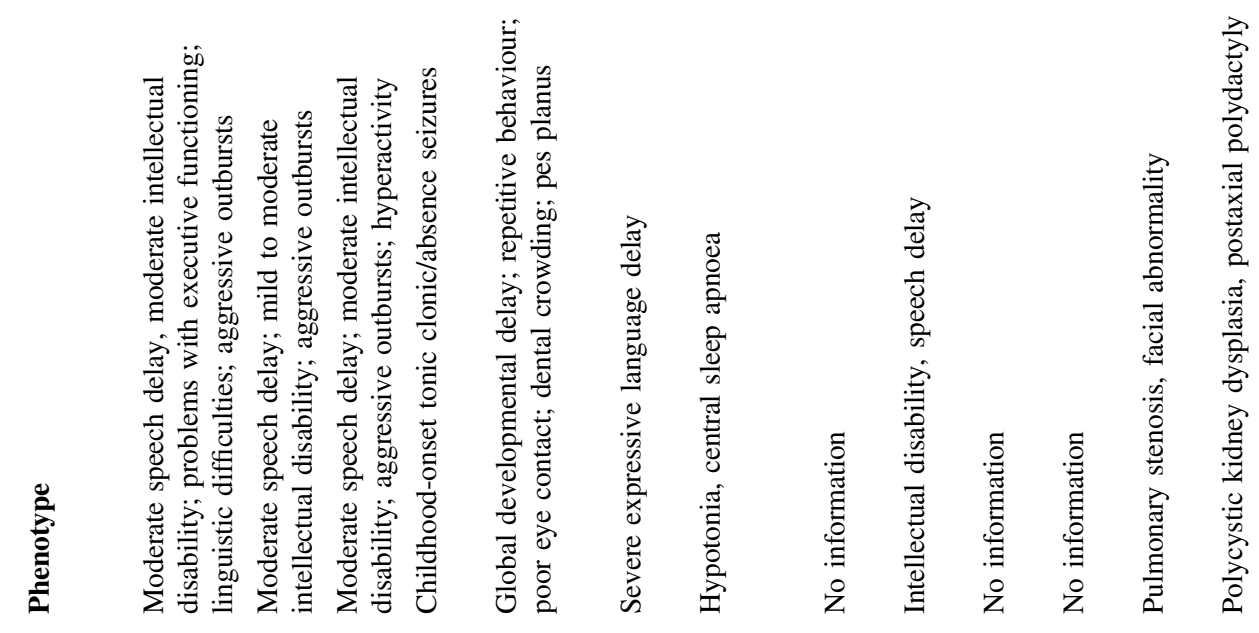

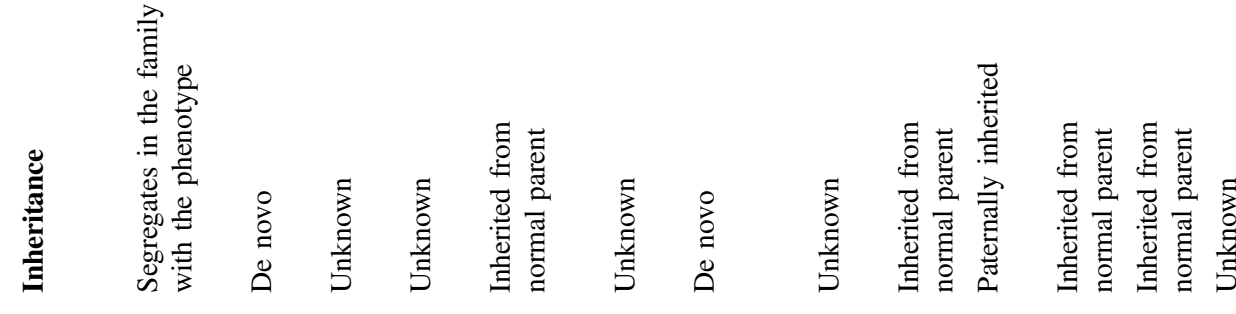

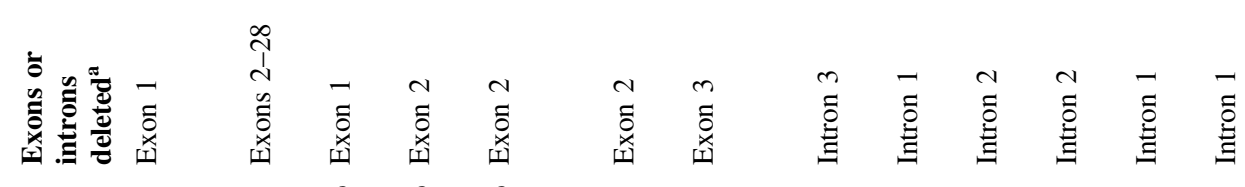

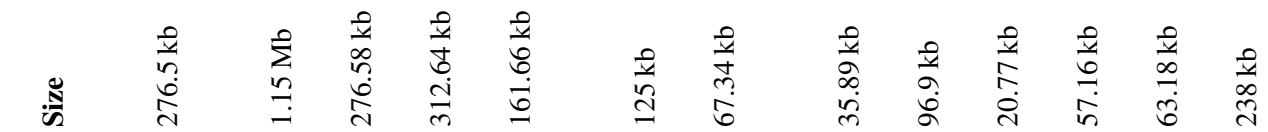
के

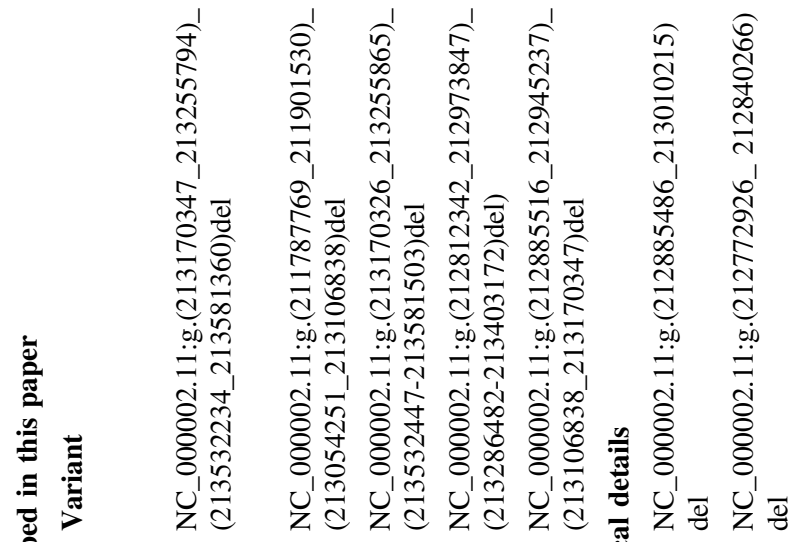

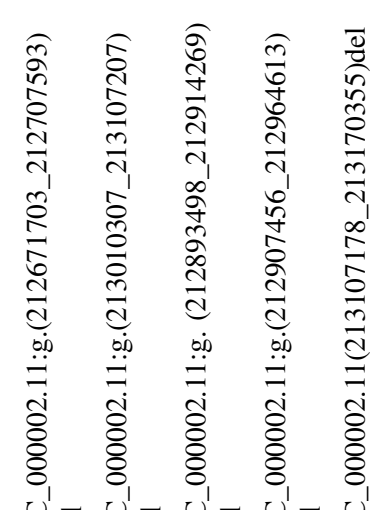

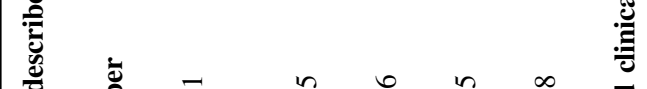

吾

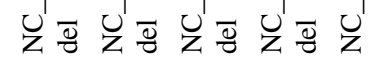

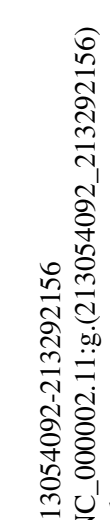

$\vec{\sim} \mathrm{z}$

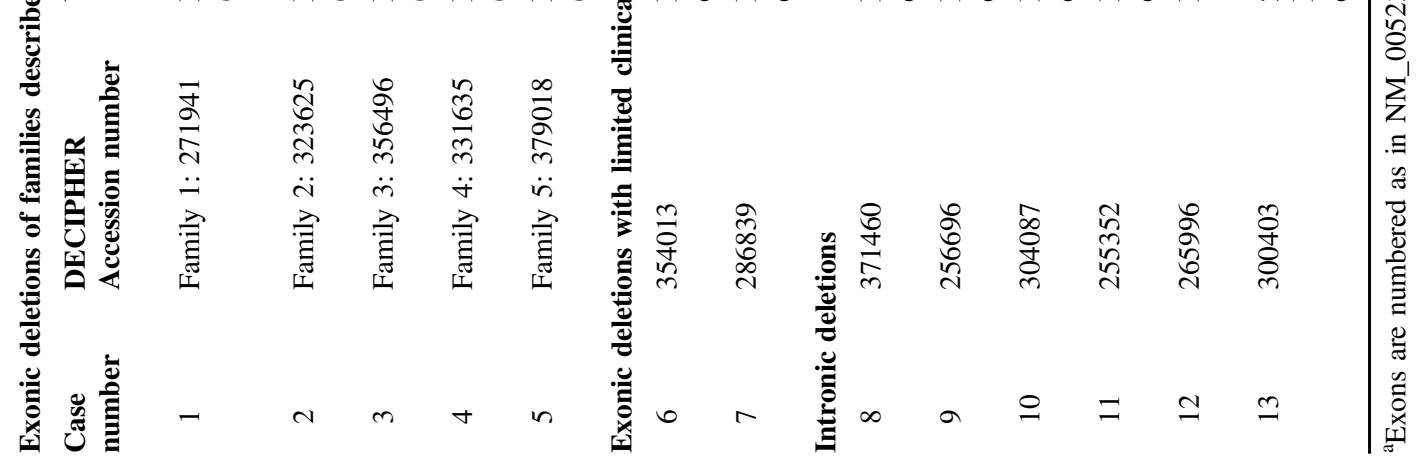




\section{Family 3}

Patient II-2 (Fig. 1A) was the second child of unrelated parents. Her father was noted to have a history of learning difficulties and dyslexia at school. The proband was born at $39+3$ weeks gestation with a birth weight of $3.28 \mathrm{kgs}$, by normal vaginal delivery. A heart murmur was detected after delivery, but an echocardiogram at 3 weeks of age showed a normal heart structure and no further cardiology follow-up was arranged. She achieved head control by 6 months, sat by 8 months and walked by 10 months. Her first words were at 2 years of age and she could speak in sentences by 5 years of age. She attended a special educational needs school and her behaviour was noted to be challenging with frequent outbursts. She was prescribed methylphenidate for attention deficit hyperactivity disorder. Examination aged 8 years showed a non-dysmorphic child with a head circumference of $49.5 \mathrm{~cm}$ ( 0.4 th centile), height $130.5 \mathrm{~cm}$ (75th centile) and weight $25.7 \mathrm{~kg}$ (50th centile). Array-CGH detected a $276.58 \mathrm{~kb}$ deletion encompassing exon 1 of ERBB4 (NC_000002.11:g.(213170326_213255865)_ (213532447-213581503)del) which was not present in her mother. Her father was not tested.

\section{Family 4}

Patient I:1 (Fig. 1A) presented at the age of 14 years with generalised seizures. Following treatment with carbamazepine for 2 years, he subsequently remained seizure-free for 20 years. He later presented at the age of 36 with tonic clonic and absence seizures. His electroencephalogram showed generalised epileptic discharges, and his MRI brain scan showed no significant abnormalities. He was prescribed levetiracetam and lamotrigine and had not had further seizures on medication. There was no history of developmental delay or ID. His clinical examination and growth parameters were normal. He has one son who had a history of febrile convulsions. A $313 \mathrm{~kb}$ deletion was identified for Patient I: 1 at chromosome $2 \mathrm{q} 34$ by arrayCGH encompassing exon 2 of ERBB4 (NC_000002.11:g. (212812342_212973847)_(213286482-213403172)del). No other family members were tested for this CNV.

\section{Family 5}

Patient I:1 (Fig. 1A) was the first child of unrelated parents of normal intellect. Following an uncomplicated pregnancy, he was born at $41+6$ weeks gestation by vaginal delivery with a birth weight of $3.29 \mathrm{~kg}$. His gross motor milestones were normal, and he walked by 12 months of age. He had two words by the age of 2 years and eight words by the age of 3 years. He was noted to have poor eye contact and repetitive behaviour. At the age of 3 years and 10 months, he could join two words together, wave goodbye, had a palmar grip, and communicated using PECS (Picture Exchange Communication System) and Makaton. He had mild tooth crowding and pes planus. His head circumference was $51.2 \mathrm{~cm}$ (26th centile), height $101.8 \mathrm{~cm}$ ( $53 \mathrm{rd}$ centile) and weight $17.7 \mathrm{~kg}$ (76th centile). Array-CGH identified a chromosome $2 \mathrm{q} 34$ deletion of $162 \mathrm{~kb}$ encompassing exon 2 of ERBB4 (NC_000002.11:g.(212885516_ 212945237)_(213106838_213170347)del). Testing for the Fragile X syndrome (OMIM 300624) did not identify FMRI expansion. The deletion was found to be inherited from unaffected mother.

\section{Intronic ERBB4 deletions}

From the six deletions from DECIPHER that were restricted to intronic regions, five cases were shown to be inherited, and in at least three instances the carrier parent was reported to be phenotypically normal. The deletion was not proven to have occurred de novo in any of the cases. The phenotype of the patients with intronic ERBB4 deletions included developmental delay, ID, pulmonary stenosis, facial abnormality, polycystic kidney dysplasia and postaxial polydactyly.

\section{Discussion}

Thus far, only one patient with ID and behavioural deficit with an intragenic ERBB4 deletion has been reported [5]. Myoclonic encephalopathy, together with psychomotor delay, has been described in another subject with a translocation resulting in disruption of ERBB4 [6]. Here, we present the largest case series of individuals with chromosome 2q34 deletions that exclusively affect ERBB4. Several observations point towards pathogenicity of the deletions involving exons of ERBB4 in autosomal dominant ID or epilepsy. Firstly, although all individuals were ascertained on the basis of their genotype, all had developmental delay or epilepsy (Table 1). Secondly, the deletion in Family 1 segregated with the phenotype and in Family 2, the deletion was shown to have arisen de novo (Fig. 1A). $E R B B 4$ is integral to developmental processes, demonstrated by HER4 knockout mice that die midembryogenesis due to cardiac malformation [12]. Notably, heterozygous null mice show delayed motor development, memory deficits and altered cue use in Morris maze learning [13]. Recovery knockout rodent models that lack HER4 brain expression have a reduced number of interneurons in the brain and cortex that is not rescued after restoring HER4 expression in adults. These rodents manifest behavioural deficits such as hyperactivity, impaired social interaction and contextual fear memory [14]. The study of ERBB4 
function in rodent models suggests that almost all cells expressing HER4 modify the effects of gammaAminobutyric acid (GABA) in the cortex, hippocampus and basal ganglia [15]. HER4 clusters and associates with GABA receptors leading to receptor internalisation, indicating its role in regulation of the interneuron network and migration of GABA neurons, the dysfunction of which may lead to a reduced number or function of cortical GABAergic neurons $[10,16]$. Tan et al. demonstrated acceleration in the progression of kindling-induced epileptogenesis in mouse models after HER4 inactivation or ERBB4 deletion [17].

In addition to ID and epilepsy, the patients in our series demonstrated clinical features such as executive functioning difficulties, attention problems, linguistic difficulties, moderate speech delay, mild motor delay, irritability, aggressive outbursts, hyperactivity, and repetitive behaviour. We note that the affected individuals from Families 1 and 3 with similar deletions encompassing exon 1 of ERBB4 share moderate speech delay, moderate ID and behavioural difficulties in common. Families 4 and 5 share deletions that include the Receptor L domain, with distinctive clinical features. Accordingly; there does not appear to be a clear correlation between the severity of ID/ epilepsy or the presence of additional clinical features, and the size or location of deletion. The reason why some exonic deletions result in ID whereas others may cause epilepsy is not clear. Aetiological overlap between ID and epilepsy is well known and could potential explain the phenotypic differences across patients, as evidenced by dominant pathogenic variants in HECW2 and GRIN2B $[18,19]$. Intriguingly, the deletion of exons $20-28$ in a patient with schizophrenia reported by Walsh et al. was shown to result in an alternative transcript deficient of the intracellular kinase domain [7]. They proposed that the alternative transcript could cause a dominant negative effect and thus disrupt neuronal migration and synaptic neurotransmission. In vitro functional studies of ALScausing mutant ERBB4 have been shown to result in reduced autophosphorylation of HER4 after stimulation with NRG1 [10]. Patient II:1 of Family 2 exhibited a large deletion of exons 2-28 encompassing both the Receptor $\mathrm{L}$ (ligand-binding) domains and tyrosine kinase domain of $E R B B 4$; with a distinct phenotype to that reported by Walsh et al. Although haploinsufficiency appears to be the most likely basis of the cases presented here, we cannot exclude other mechanisms without functional studies.

Interestingly, the ERBB 4 deletion in Family 5 was found to be maternally inherited, though maternal intellect in I:2 was reportedly normal. It is possible that reduced penetrance and variable expressivity associated with ERBB4 haploinsufficiency could be explained by differences in the genetic background or in the levels of expression of the remaining allele. Further investigation and functional work incorporating additional patients with $E R B B 4$ variants is required to fully ascertain their consequence on protein function and resulting phenotype.

We propose that deletions that exclusively affect the intronic regions of $E R B B 4$ are less likely to be pathogenic. This is based on the following observations-individuals with the intronic deletions did not display consistent phenotypes, and intronic deletions were inherited from unaffected parents in several patients (Table 1) (Fig. 1). Furthermore, several other ERBB4 intronic deletions are seen in control populations on the Database of Genomic Variants (DGV) and these observations are similar to what is observed with NRXN1 exonic and intronic deletions $[20,21]$.

In summary, we demonstrate that $2 \mathrm{q} 34$ deletions that result in loss of exons of ERBB4 may cause autosomal dominant mild to moderate developmental delay, ID or epilepsy. CNVs can help to identify novel disease-genes [22-24]. This study, therefore, adds ERBB4 as a likely new candidate gene for ID. Future work will be required to identify if point variants in ERBB4 also cause ID.

Acknowledgements This study makes use of data generated by the DECIPHER community. A full list of centres who contributed to the generation of the data is available from http://decipher.sanger.ac.uk and via email from decipher@sanger.ac.uk. One of the/The author(s) of this publication are (a) member(s) of the European Reference Network on Rare Congenital Malformations and Rare Intellectual Disability ERN-ITHACA [EU Framework Partnership Agreement ID: 3HP-HP-FPA ERN-01-2016/739516].

\section{Compliance with ethical standards}

Conflict of interest The authors declare that they have no conflict of interest.

Publisher's note Springer Nature remains neutral with regard to jurisdictional claims in published maps and institutional affiliations.

Open Access This article is licensed under a Creative Commons Attribution 4.0 International License, which permits use, sharing, adaptation, distribution and reproduction in any medium or format, as long as you give appropriate credit to the original author(s) and the source, provide a link to the Creative Commons license, and indicate if changes were made. The images or other third party material in this article are included in the article's Creative Commons license, unless indicated otherwise in a credit line to the material. If material is not included in the article's Creative Commons license and your intended use is not permitted by statutory regulation or exceeds the permitted use, you will need to obtain permission directly from the copyright holder. To view a copy of this license, visit http://creativecommons. org/licenses/by/4.0/.

\section{References}

1. Karczewski KJ, Francioli LC, Tiao G, Cummings BB, Alföldi J, Wang Q, et al. The mutational constraint spectrum quantified from variation in 141,456 humans. Nature. 2020;581:434-43. 
2. Law AJ, Kleinman JE, Weinberger DR, Weickert CS. Diseaseassociated intronic variants in the ErbB4 gene are related to altered ErbB4 splice-variant expression in the brain in schizophrenia. Hum Mol Genet. 2007;16:129-41.

3. Srinivasan R, Poulsom R, Hurst HC, Gullick WJ. Expression of the c-erbB-4/HER4 protein and mRNA in normal human fetal and adult tissues and in a survey of nine solid tumour types. J Pathol. 1998;185:236-45.

4. Mechawar N, Lacoste B, Yu W-F, Srivastava LK, Quirion R. Developmental profile of neuregulin receptor ErbB4 in postnatal rat cerebral cortex and hippocampus. Neuroscience. 2007;148:126-39.

5. Kasnauskiene J, Ciuladaite Z, Preiksaitiene E, Utkus A, Peciulyte A, Kučinskas V. A new single gene deletion on 2q34: ERBB4 is associated with intellectual disability. Am J Med Genet. 2013;161:1487-90.

6. Backx L, Ceulemans B, Vermeesch JR, Devriendt K, Van, Esch $\mathrm{H}$. Early myoclonic encephalopathy caused by a disruption of the neuregulin-1 receptor ErbB4. Eur J Hum Genet. 2009;17:378-82.

7. Walsh T, McClellan JM, McCarthy SE, Addington AM, Pierce SB, Cooper GM, et al. Rare Structural Variants Disrupt Multiple Genes in Neurodevelopmental Pathways in Schizophrenia. Science. 2008;320:6.

8. Prasad A, Merico D, Thiruvahindrapuram B, Wei J, Lionel AC, Sato $\mathrm{D}$, et al. A discovery resource of rare copy number variations in individuals with autism spectrum disorder. G3 (Bethesda). 2012;2:1665-85.

9. Feng Y, Cheng D, Zhang C, Li Y, Zhang Z, Wang J, et al. Association between ErbB4 single nucleotide polymorphisms and susceptibility to schizophrenia: a meta-analysis of case-control studies. Medicine. 2017;96:e5920.

10. Takahashi Y, Fukuda Y, Yoshimura J, Toyoda A, Kurppa K, Moritoyo $\mathrm{H}$, et al. ERBB4 mutations that disrupt the neuregulinErbB4 pathway cause amyotrophic lateral sclerosis type 19. Am J Hum Genet. 2013;93:900-5.

11. Firth HV, Richards SM, Bevan AP, Clayton S, Corpas M, Rajan D, et al. DECIPHER: database of chromosomal imbalance and phenotype in humans using ensembl resources. Am J Hum Genet. 2009;84:524-33.

12. Gassmann M, Casagranda F, Orioli D, Simon H, Lai C, Klein R, et al. Aberrant neural and cardiac development in mice lacking the ErbB4 neuregulin receptor. Nature. 1995;378:390-4.

13. Golub MS, Germann SL, Lloyd KCK. Behavioral characteristics of a nervous system-specific erbB4 knock-out mouse. Behav Brain Res. 2004;153:159-70.
14. Wang H, Liu F, Chen W, Sun X, Cui W, Dong Z, et al. Genetic recovery of ErbB4 in adulthood partially restores brain functions in null mice. Proc Natl Acad Sci USA. 2018;115:13105-10.

15. Bean JC, Lin TW, Sathyamurthy A, Liu F, Yin D-M, Xiong W-C, et al. Genetic labeling reveals novel cellular targets of schizophrenia susceptibility gene: distribution of GABA and NonGABA ErbB4-positive cells in adult mouse brain. J Neurosci. 2014;34:13549-66.

16. Mitchell RM, Janssen MJ, Karavanova I, Vullhorst D, Furth K, Makusky A, et al. ErbB4 reduces synaptic GABAA currents independent of its receptor tyrosine kinase activity. Proc Natl Acad Sci USA. 2013;110:19603-8.

17. Tan G-H, Liu Y-Y, Hu X-L, Yin D-M, Mei L, Xiong Z-Q. Neuregulin 1 represses limbic epileptogenesis through ErbB4 in parvalbumin-expressing interneurons. Nat Neurosci. 2012;15:258-66.

18. Halvardson J, Zhao JJ, Zaghlool A, Wentzel C, Georgii-Hemming $\mathrm{P}$, Månsson E, et al. Mutations in HECW2 are associated with intellectual disability and epilepsy. $\mathrm{J}$ Med Genet. 2016;53:697-704.

19. Lemke JR, Hendrickx R, Geider K, Laube B, Schwake M, Harvey RJ, et al. GRIN2B mutations in West syndrome and intellectual disability with focal epilepsy. Ann Neurol. 2014;75:147-54.

20. MacDonald JR, Ziman R, Yuen RKC, Feuk L, Scherer SW. The database of genomic variants: a curated collection of structural variation in the human genome. Nucleic Acids Res. 2014;42: D986-92. Database issue

21. Lowther C, Speevak M, Armour CM, Goh ES, Graham GE, Li C, et al. Molecular characterization of NRXN1 deletions from 19,263 clinical microarray cases identifies exons important for neurodevelopmental disease expression. Genet Med. 2017;19:53-61.

22. Mucha BE, Banka S, Ajeawung NF, Molidperee S, Chen GG, Koenig MK, et al. Correction: a new microdeletion syndrome involving TBC1D24, ATP6V0C, and PDPK1 causes epilepsy, microcephaly, and developmental delay. Genet Med. 2019;21:2159-60.

23. Kasher PR, Schertz KE, Thomas M, Jackson A, Annunziata S, Ballesta-Martinez MJ, et al. Small 6q16.1 deletions encompassing POU3F2 cause susceptibility to obesity and variable developmental delay with intellectual disability. Am J Hum Genet. 2016;98:363-72.

24. Cuvertino S, Stuart HM, Chandler KE, Roberts NA, Armstrong R, Bernardini L, et al. ACTB Loss-of-function mutations result in a pleiotropic developmental disorder. Am J Hum Genet. 2017;101:1021-33. 